CLINICAL STUDY

\title{
Impact of clinical, hormonal, radiological, and immunohistochemical studies on the diagnosis of postmenopausal hyperandrogenism
}

Julie Sarfati, Anne Bachelot, Christiane Coussieu ${ }^{1}$, Géri Meduri ${ }^{2,3}$, Philippe Touraine and on behalf of the Study Group Hyperandrogenism in Postmenopausal Women ${ }^{\dagger}$

AP-HP, Department of Endocrinology and Reproductive Medicine, Groupe Hospitalier Pitié-Salpêtrière, Centre de Référence des Maladies Endocriniennes Rares de la Croissance, Université, Pierre et Marie Curie, Paris VI, 75013 Paris, France, ${ }^{1}$ Department of Hormonal Biochemistry, Groupe Hospitalier PitiéSalpêtrière, 75013 Paris, France, ${ }^{2}$ Unité de Recherche, INSERM, U-693, Hormones, Genes and Reproduction, Le Kremlin Bicetre, France and ${ }^{3}$ AP-HP, Service de Génétique Moléculaire Hormonologie et Pharmacogénétique Hôpital Bicêtre, 94275 Le Kremlin Bicetre, France

(Correspondence should be addressed to P Touraine; Email: philippe.touraine@psl.aphp.fr)

${ }^{\dagger}$ (see Acknowledgements section for details)

\begin{abstract}
Objective: Evaluation of postmenopausal women with suspicion of androgen-secreting tumor. Design and patients: We retrospectively studied 22 postmenopausal women referred to our center for suspicion of androgen-secreting tumor. All patients had clinical, biological, and morphological evaluation. In absence of adrenal tumors, ovarian surgery was most often proposed and immunohistochemistry (IHC) studies were performed.

Results: Ovarian tumors were detected by ultrasound and/or magnetic resonance imaging in eight patients. Two adrenal androgen-secreting tumors were diagnosed by an adrenal computed tomography (CT) scan. The clinical presentation of the women with or without tumors was similar. Nevertheless, women with tumor exhibited significantly higher testosterone levels and lower basal FSH and LH levels than the other women $(2.6 \pm 2.7 \mathrm{vs} 0.9 \pm 0.9 \mathrm{ng} / \mathrm{ml}, P<0.05 ; 26.5 \pm 22.9$ vs $66.5 \pm$ $26.0 \mathrm{IU} / \mathrm{l}, \mathrm{P}<0.01$; and $12.0 \pm 8.6$ vs $24.1 \pm 8.9 \mathrm{IU} / \mathrm{l}, P<0.05$ respectively). Based on a likelihood ratio test, patients with a tumor had 8.4 and 10.8 times higher risk of having a testosterone level $\geq 1.4 \mathrm{ng} / \mathrm{ml}$ or an FSH level $\leq 35 \mathrm{IU} / \mathrm{l}$. Finally, IHC analysis with an anti-P450c17 $\alpha$ antibody allowed the identification of an elevated number of ovarian androgen-producing cells in five patients in whom no tumor was found.

Conclusions: Androgen-secreting tumors are clinically difficult to discriminate from other causes of postmenopausal hyperandrogenism. Testosterone and FSH were the two discriminative markers in a multivariate analysis. Ovarian and adrenal tumors were detected by imaging studies. However, ovarian non-tumoral causes of hyperandrogenism may be difficult to detect with conventional histology.
\end{abstract}

European Journal of Endocrinology 165 779-788

\section{Background}

Clinical signs of androgen excess may occur during menopause as part of the normal aging process but biochemical androgen excess connotes a pathogenesis in older women as in cycling women. The main differential diagnosis of androgen excess in postmenopausal women is either tumoral causes, namely androgen-secreting ovarian or adrenal tumors, or non-tumoral causes, i.e. polycystic ovarian syndrome, hyperthecosis, Cushing's syndrome, congenital adrenal hyperplasia, and iatrogenesis (see for review (1)). Symptoms of androgen excess are associated with a tumoral pathology in $<1 \%$ of women of all ages (2-5). Androgen-producing ovarian tumors include lipoid, Leydig cell, granulosa-theca cell, and Sertoli-stromal cell tumors $(6,7)$. Adrenal androgen-secreting tumors are rare but highly suggestive of malignancy (8). The main non-tumoral cause of postmenopausal ovarian biochemical hyperandrogenism seems to be ovarian hyperthecosis (9). This typically bilateral condition is characterized by a hyperplastic ovarian stroma associated with cellular luteinization and is believed to result from abnormal ovarian steroidogenesis secondary to gonadotropic stromal hyperstimulation (10-13). It is classically associated with insulin resistance and hyperinsulinemia in almost all reported cases (12, 14, 15), but, in contrast to polycystic ovary syndrome, the mechanisms correlating hyperinsulinemia and hyperthecosis remain unstudied (16-18). This pathology is benign and must be differentiated from androgen-producing tumors. However, to date, 
biochemical hyperandrogenism in postmenopausal patients is a poorly characterized condition whose prevalence and multiple etiologies have never been evaluated. Furthermore, no discriminating factors between tumoral and non-tumoral etiology have been established in postmenopausal patients. Ovarian and/or adrenal venous sampling can be helpful (19), but the diagnostic specificity of this technique seems disappointing even in experienced hands (4) and there is no need to lateralize an ovarian tumor in postmenopausal patients. The performance of a 2- to 5-day low-dose dexamethasone suppression test has been suggested, but this approach has not been studied for hyperandrogenism in postmenopausal women (20). Finally, there are small and contradictory results concerning the discriminatory effect of gonadotropin suppression in the evaluation of postmenopausal hyperandrogenism (12, 21). Immunohistochemical analysis is not directly involved in discriminating tumor lesions from nontumor pathology but has already been used to elucidate the mechanism of an ovarian tumoral hyperandrogenism (22). The expression of steroidogenic enzymes in human ovaries has been studied and it has been shown that the steroidogenic enzymes are either absent or present in a limited percentage of cells in postmenopausal ovaries (23-25).

The main aim of our study was then to build up a detailed phenotype of postmenopausal biochemical hyperandrogenism. We thus looked for the possible presence of specific characteristics permitting to discriminate between tumoral or non-tumoral postmenopausal biochemical hyperandrogenism. We then decided to specify the diagnosis by using ovarian immunohistochemical analysis in five women in which the ovarian conventional histology was negative despite being a confirmed ovarian source of androgens (sharp decrease in testosterone level after bilateral ovariectomy).

\section{Patients and methods}

\section{Patients}

This retrospective study included 22 consecutive postmenopausal women with biochemical hyperandrogenism referred to our center between 1995 and 2009. All these women have natural menopause over 40 years and were referred to our center for the apparition of clinical signs suggesting the presence of an androgensecreting tumor. Testosterone dosage confirmed the presence of hyperandrogenism, with testosterone levels superior to the normal range of testosterone for cycling women $(>0.4 \mathrm{ng} / \mathrm{ml}$ or $1.4 \mathrm{nmol} / \mathrm{l})(26)$. As there is a decline in androgens with age, a biochemical androgen level higher than the normal range for cyclical women was a restrictive criterion in our postmenopausal population, permitting selection of women for whom clinicians must rule out a tumoral diagnosis $(27,28)$. All women had clinical, hormonal, and morphological evaluation. The clinical data taken into consideration were age at investigation, time lapse since menopause, clinical signs of hyperandrogenism and virilization (hirsutism, alopecia, deepening of the voice, and clitoromegaly (29)), clinical signs of hyperestrogenism (postmenopausal bleeding, mastodynia $>5$ days/month, and hormonal impregnation of a cervical smear without hormonal treatment), clinical signs of Cushing's syndrome, the onset of symptoms, and, finally, the presence or absence of associated clinical signs of metabolic syndrome, i.e. overweight or obesity (body mass index (BMI) $\geq 25$ and $30 \mathrm{~kg} / \mathrm{m}^{2}$ respectively), type 2 diabetes, and high blood pressure (systolic $>160 \mathrm{mmHg}$ and/or diastolic $>90 \mathrm{mmHg}$ ). Hormonal measurements included FSH, LH, testosterone, androstenedione, estradiol $\left(\mathrm{E}_{2}\right)$, DHEA-S, and sex hormone binding globulin (SHBG) determination. Morphological evaluation was performed by pelvic sonography and/or magnetic resonance imaging (MRI). In the absence of adrenal tumors or Cushing's syndrome, resection of both ovaries was proposed for these women.

\section{Hormone measurements}

All hormone measurements were performed in a single assay. Plasma LH and FSH were measured by immunofluorometric assay (Cis-Bio, Gif-sur-Yvette, Paris, France). The intra- and inter-assay coefficients of variation (CV) were 1.5 and $5.2 \%$ for $\mathrm{LH}$ and 2.6 and $4 \%$ for FSH respectively. The detection limit was $0.15 \mathrm{IU} / \mathrm{l}$ in both assays. Testosterone concentration was determined by RIA (Orion Diagnostica, Esproo, Finland). The intra-assay CV was between 3.8 and $7.5 \%$ and inter-assay CV between 4.8 and $7 \%$. The sensitivity of the testosterone assay was $0.029 \mathrm{ng} / \mathrm{ml}$ (domain of measurement from 0.14 to $14.4 \mathrm{ng} / \mathrm{ml}$ ). Androstenedione concentration was determined by RIA (Immunotech, Marseille, France). The intra- and inter-assay CV was $\leq 8.1$ and $\leq 11.9 \%$. $\mathrm{E}_{2}$ concentration was determined by RIA (DiaSorin, Antony, France). The intra-assay CV was between 2.6 and $6.1 \%$ and interassay CV was between 4.6 and $6.1 \%$. DHEA-S plasma levels were measured by conventional RIA (Immunotech, Beckman Coulter, Ville-pinte, France). Normal range was based on the results obtained from healthy women during a normal menstrual cycle and provided by our laboratory of hormonal investigations. The intraassay CV varied from 2.6 to $8.1 \%$ whereas the interassay CV varied from 3.7 to $11.9 \%$.

The SHBG was measured by a commercially available RIA (Chemiluminescence, Roche modular). Blood was collected and plasma was immediately separated by centrifugation for $15 \mathrm{~min}$ at $-4{ }^{\circ} \mathrm{C}$ and was stored at $-20{ }^{\circ} \mathrm{C}$ until assayed.

\section{Imaging studies}

Grayscale and color Doppler ultrasonography were obtained in the longitudinal and transverse planes by 
using an anterior and a transvaginal approach. All ultrasonographic examinations were performed by a staff radiologist experienced in pelvic ultrasound.

The MR studies were performed using a 1.5-T scanner (Magnetom Vision, Siemens, Erlangen, Germany), body phased-array coil, for imaging of the ovaries. Unenhanced T1-weighted images $(\mathrm{TR} / \mathrm{TE}=$ $800 \mathrm{~ms} / 12 \mathrm{~ms}$, matrix $150 ¥ 256$, number of excitations $=2)$ and $\mathrm{T} 2$-weighted images $(\mathrm{TR} / \mathrm{TE}=$ $4400 \mathrm{~ms} / 132 \mathrm{~ms}$, matrix $150 ¥ 256$, number of excitations $=3$ ) of the ovaries in the sagittal plane, with and without fat suppression, were obtained. Enhanced T1weighted images were obtained immediately after i.v. administration of $15 \mathrm{ml}$ gadolinium (dose: $0.1 \mathrm{mmol} / \mathrm{kg}$ over $6 \mathrm{~s}$ with a flow rate of $2.5 \mathrm{ml} / \mathrm{s}$ ). Pre- and post-contrast images were subtracted. Adrenal helicoidal CT scan with contiguous 3-mm-thick slices was performed in 16 patients.

\section{Histological and immunocytochemical studies of the ovaries}

The formol-fixed and paraffin-embedded ovarian biopsies of the five patients without a cause of hyperandrogenism detectable by conventional histology were available for further studies. Immunohistochemistry (IHC) was performed as described previously on deparaffinized serial tissue sections after microwave antigen retrieval in $\mathrm{pH} 6$ citrate buffer or Tris-EDTA $\mathrm{pH}$ 9 buffer for P450c17 $\alpha$ and luteinizing hormone receptor (LHR) immunodetection respectively. The sections were then incubated overnight with the antiP450c17 antibody (30) (dilution 1/5000) or with the LHR29 MAB (31) (at the concentration of $12 \mu \mathrm{g} / \mathrm{ml}$ ) at $4{ }^{\circ} \mathrm{C}$ in a humid chamber. Serial sections incubated with rabbit IgG and mouse IgG1 immunoglobulins at the same concentrations as the specific antibodies were used as negative controls. After primary antibody incubation, endogenous peroxidases were quenched with $3 \% \mathrm{H}_{2} \mathrm{O}_{2}$ in PBS ( $\mathrm{pH} 7.4$ ) for $5 \mathrm{~min}$ and the bound immunoglobulins were revealed with a commercial biotin-free immunolabeling kit (IMMPRESS kit Vector, Burlingame, CA, USA). Aminoethylcarbazole (SigmaAldrich Chemical Co.) was used as a chromogen, and the sections were counterstained with Mayer's hematoxylin. Each experiment was performed at least twice on nonconsecutive sections of each ovarian tissue sample. Microscopical examination was performed with a conventional optical microscope (Provis, Olympus, Tokyo, Japan).

\section{Statistical analysis}

Descriptive statistics were performed for each variable; quantitative results are presented as individual values in the figures and tables and as mean \pm s.D. in the text; qualitative results are presented as a distribution of a number of patients. Between-group comparisons were performed using the Mann-Whitney non-parametric test and correlations between variables were described using Spearman's correlation coefficients. Proportions for the two groups were compared using a $\chi^{2}$ test or a Fisher's exact test, when appropriate. A $P$ value $<0.05$ was accepted as significant. Parameters with $P$ values $\leq 0.2$ in the univariate analysis were included in a multivariate logistic regression analysis. The predictive accuracy of the model was measured by the area under the receiver operating characteristic (ROC) curve. Cut-off values for significant biological markers in the logistic model were then determined using an ROC curve. According to Youden's index, appropriate cut-off values for the hormone levels were selected as those maximizing the sum (specificity + sensitivity). To construct confidence interval (CI) for sensitivity and specificity, we used the binomial tables. A likelihood ratio (LR) test was then calculated.

\section{Results}

Clinical, biological, and pathological features of the 22 women of the two groups are presented in Table 1.

\section{Etiology of hyperandrogenism}

Ten of the 22 women with postmenopausal hyperandrogenism had a tumor (T group, Table 1). Two of them had an adrenal tumor detected at tomography. Both were carcinomas (Weiss score $>3$ ), one was an androgen-secreting tumor and the other an androgenand cortisol-secreting tumor. Eight patients had ovarian tumors. The neoplastic cells were the androgen source in six of these patients, two had fibrothecomas, two had Leydig cell tumors, one had Sertoli-Leydig cell, and one had a granulosa cell tumor. The remaining two patients had a bilateral metastatic endocrine ovarian tumor and a serous cystadenoma, respectively, both associated with ovarian stromal hyperplasia. In one of these patients, it was demonstrated that the ectopic human chorionic gonadotropin (hCG) produced by tumor cells stimulated steroid production by the ovarian stroma (22).

The other 12 women with non-tumoral conditions (NT group, Table 1) had various afflictions: one suffered from Cushing's disease, one from pseudo-Cushing's syndrome, and four cases underwent spontaneous resolution. The remaining six patients had a bilateral ovariectomy revealing a serous cyst and a mucous cyst in two of them, both associated with a normal stroma, an isolated stromal hyperplasia in one patient, and a normal histology in the remaining three patients. 


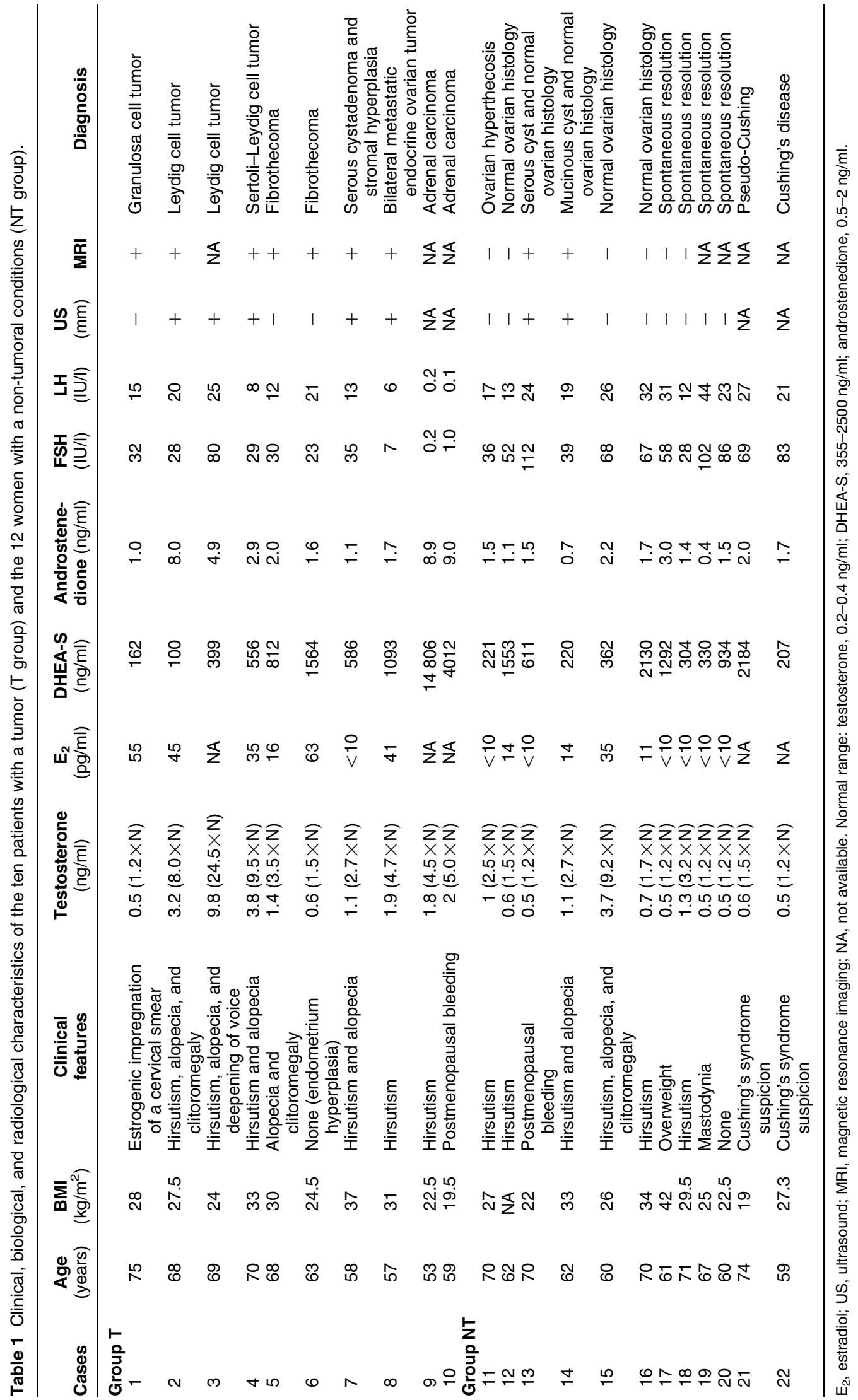




\section{Comparison between the T and NT groups}

Clinical characteristics There were no statistical differences between the two groups concerning mean age at investigation and mean time since menopause $(64.0 \pm 7.0$ and $65.5 \pm 5.3$ years, respectively in the $T$ and NT groups; Table 1). Hirsutism was more frequent in the tumor group $(6 / 10(60 \%)$ vs $6 / 12(50 \%))$ with no statistical difference. Alopecia was the most frequent but not statistically different, sign of virilization noted; it was found in $50 \%$ of the T group (5/10) and in $17 \%$ of the NT group (2/12). Other signs of virilization were rare, three patients had clitoromegaly, two in the T group, one in the NT group, and one reported a deepening voice (patients no. 2, 5, 15, and 3 respectively, Table 1). Onset of symptoms as perceived by patients was 20.5 \pm 17.0 months (range: 3.0-48.0 months) versus 132.6 \pm 261.3 months (range: 9.0-600.0 months) in the T and NT groups, respectively, without statistical differences. Only one patient in the NT group had a long history of clinical hyperandrogenism (patient no. 18, Table 1) from early adulthood associated with infertility and probably secondary to an undiagnosed polycystic ovary syndrome (32). There were also no statistically significant differences between the two groups concerning the prevalence of associated clinical signs of a metabolic syndrome, i.e. BMI $\geq 25 \mathrm{~kg} / \mathrm{m}^{2}$, diabetes mellitus, and high blood pressure $(6 / 10$ (60\%) vs $8 / 11(73 \%), 2 / 9(22 \%)$ vs $5 / 12(42 \%)$, and $4 / 9$ $(44 \%)$ vs $7 / 12(58 \%)$ respectively).

Biological characteristics Mean testosterone and mean $\mathrm{E}_{2}$ levels were significantly higher in the $\mathrm{T}$ than in the NT group $(2.6 \pm 2.7$ vs $0.9 \pm 0.9 \mathrm{ng} / \mathrm{ml}, P<0.05$ and $80.0 \pm 122.7$ vs $11.3 \pm 8.9 \mathrm{pg} / \mathrm{ml}, \quad P<0.01$ respectively; Fig. $1 \mathrm{~A}$ and $\mathrm{B})$ with an extremely large range of testosterone levels in the $\mathrm{T}$ group. Mean androstenedione levels were higher in the $\mathrm{T}$ than in the NT group $(4.1 \pm 3.3$ vs $1.5 \pm 0.7 \mathrm{ng} / \mathrm{ml}, P=0.07)$. Conversely, mean basal FSH $(26.5 \pm 22.9$ and 66.5 $\pm 26.0 \mathrm{IU} / \mathrm{l}, \mathrm{P}<0.01$; Fig. $1 \mathrm{C}$ ) and mean basal LH levels $(12.0 \pm 8.6$ and $24.1 \pm 8.9 \mathrm{IU} / \mathrm{l}, \mathrm{P}<0.05$; Fig. 1D) were significantly lower in the T than in the NT group. Only two patients (no. 9 and 10) with adrenal carcinomas had suppressed levels of FSH and LH (range: 0.1-2 IU/l). Only in the NT group, there is a significant correlation between testosterone and $\mathrm{E}_{2}$ levels $(P=0.0003)$.

A binary logistic regression analysis was performed to determine the discriminating power of these features. Two biological markers were significant in the model: basal testosterone and basal FSH levels. The predictive accuracy for the model including these two parameters, as measured by the area under the ROC curve, was of 0.97. Predictive accuracy for basal testosterone levels alone and for basal FSH levels alone was of 0.82 and 0.90 respectively. Cut-off values maximizing sensitivity and specificity for the two significant biological markers in the logistic regression model are provided in Table 2.
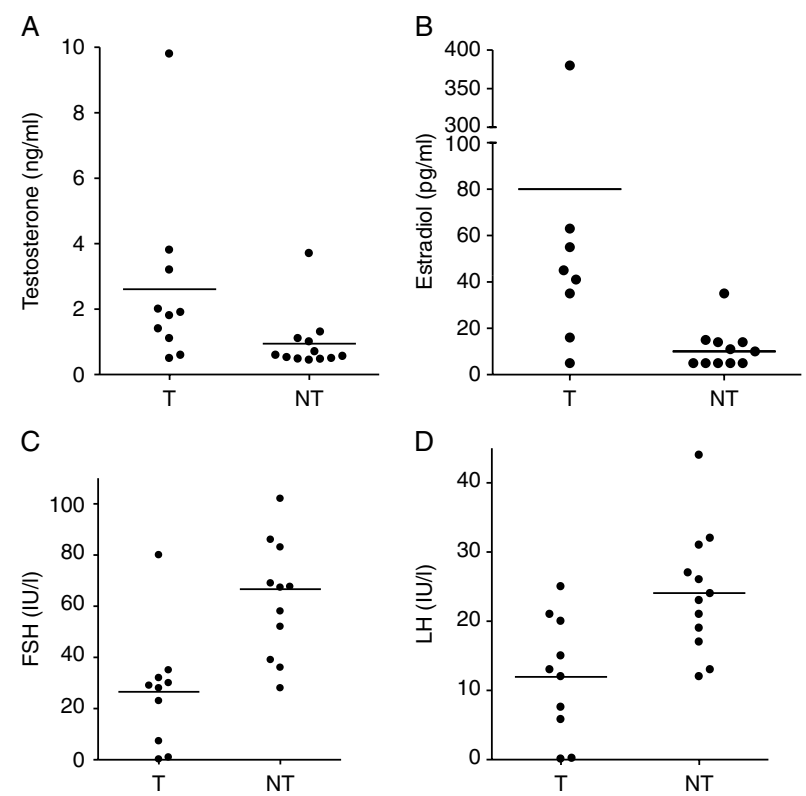

Figure 1 Individual values of serum total testosterone (A), estradiol (B), FSH (C), and LH levels (D). A significant difference between the two groups is observed in testosterone $(P<0.05)$, estradiol $(P<0.01)$, basal FSH $(P<0.01)$, and basal LH $(P<0.05)$.

The likelihood ratio (LR) when affected by a tumor in this population was 8.4 and 10.8 for basal testosterone level $\geq 1.4 \mathrm{ng} / \mathrm{ml}(3.5 \times \mathrm{N})$ and $\mathrm{FSH} \leq 35 \mathrm{IU} / \mathrm{l}$ respectively. Consequently, a postmenopausal woman with a tumoral pathology has 8.4 and 10.8 times higher risk for presenting basal testosterone level $\geq 1.4 \mathrm{ng} / \mathrm{ml}$ $(3.5 \times \mathrm{N})$ or basal FSH level $\leq 35 \mathrm{IU} / \mathrm{l}$.

Radiological characteristics according to tumor type Sixteen patients had a CT scan, permitting the diagnosis of adrenal carcinomas in two of them. Eighteen ovarian sonographies were performed, eight in the $\mathrm{T}$ and ten in the NT groups (see Table 1). Ultrasonography showed ovarian masses in seven patients: five tumors were diagnosed in the $\mathrm{T}$ group and two cystic formations were identified in the NT group. Eleven ovarian sonographies (patients no. 1, 5, and 6) were normal. The ovarian sonography score was positive predictive value $(\mathrm{PPV})=5 /(5+2)=71 \%$ and negative predictive value $(\mathrm{NPV})=8 /(8+3)=73 \%$. Fifteen patients had an ovarian MRI, seven in the $\mathrm{T}$ and eight in the NT groups (see Table 1). Seven tumors were diagnosed in the $\mathrm{T}$ and two cystic formations in the NT groups. The ovarian MRI score was $\mathrm{PPV}=7 / 9=$ $78 \%$ and $\mathrm{NPV}=8 / 8=100 \%$.

\section{IHC studies of histologically normal ovaries}

The ovarian source of androgens in five patients with hyperandrogenemia of unequivocal ovarian origin (patients no. 12-16, Table 1) could not be identified 
Table 2 Sensitivity and specificity of testosterone and FSH levels in diagnosis of tumoral and non-tumoral hyperandrogenism in postmenopausal women. Thresholds were selected using Youden's index, as described in the Materials and methods section.

\begin{tabular}{lccr}
\hline & $\begin{array}{c}\text { Sensitivity \% } \\
(\mathrm{Cl})\end{array}$ & $\begin{array}{c}\text { Specificity \% } \\
(\mathrm{Cl})\end{array}$ & LR + \\
\hline $\mathrm{TT} \geq 1.4 \mathrm{ng} / \mathrm{ml}$ & $70(39-89)$ & $92(62-100)$ & 8.4 \\
$\mathrm{FSH} \leq 35 \mathrm{IU} / \mathrm{l}$ & $90(57-100)$ & $92(62-100)$ & 10.8 \\
\hline
\end{tabular}

$\mathrm{Cl}$, 95\% confidence intervals; LR+, likelihood ratio; TT, total testosterone.

by conventional histology. However, immunohistology allowed detecting numerous steroidogenic cells expressing the P450c17 $\alpha$ enzyme involved in androgen synthesis in all cases and demonstrating LH receptors expression in three cases.

In patients no. 14 and 16 , the androgen-producing cells were situated in the ovarian medulla and hilus (Fig. 2A and E), they had a round nucleus, polygonal shape and abundant cytoplasm, with lipid vacuoles (Fig. 2C and G), and expressed P450c17 $\alpha$ (CYP17A1) (Fig. 2B, D and F, H arrow), about $20 \%$ of these cells were also LHR immunopositive (Fig. 3A and B).

In patients no. 12 (Fig. 2I), 13, and 15, androgenproducing cells were situated in the cortical stroma but had a different aspect.

The stromal androgen-producing cells of patients no. 12 and 15 were large, luteinized, with abundant vacuolated cytoplasm (Fig. 2I, $\mathrm{K}$ and $\mathrm{M}, \mathrm{O}$ ), and strongly steroidogenic (Fig. 2J, L and N, P). They were LHR negative in patient no. 12 and LHR positive $(25 \%)$ in patient no. 15 (Fig. 3C).

The cortical androgen-producing cells in the ovary of patient no. 13, situated near a benign serous cyst, were fibroblast like, elongated, and with scanty cytoplasm (Fig. 2Q and S) and strongly immunopositive for P450c17 $\alpha$ (Fig. 2R and T). No residual material was available for LHR immunodetection.

The control sections for both P450c17 $\alpha$ (not shown) and for LHR immunolabeling (Fig. 3D-F) were negative.

\section{Discussion}

We describe the first cohort of exclusively postmenopausal patients with biochemical hyperandrogenism. This inclusion criterion was necessary to select women in whom the presence of a tumoral pathology was suspected and must be excluded by the clinicians. The cohort comprised 22 women, among whom ten were affected by an androgen-producing tumor. This finding demonstrates that a relevant number of cases of postmenopausal hyperandrogenism have a tumoral origin and underlines the importance of a correct diagnosis.

The clinical presentation was remarkably similar in both the T and the NT groups. Surprisingly, clinical signs of hyperandrogenism were not always present.
Indeed, three patients in the $\mathrm{T}$ group, two bearing ovarian tumors, and one with an adrenal carcinoma (patients no. 1, 6, and 10, Table 1) presented signs of hyperestrogenism such as postmenopausal bleeding, endometrial hyperplasia, or signs of estrogenic impregnation on a cervical smear. Indeed, these tumors may induce estrogen excess $(33,34)$.

The onset of clinical manifestations of hyperandrogenism and their progression were not different in the two groups. Thus, in contrast to current wisdom, a clinical presentation characterized by rapidly progressive hyperandrogenism is not always associated with a tumor as described previously $(20,35)$. Indeed, some tumors in our study only induced moderately

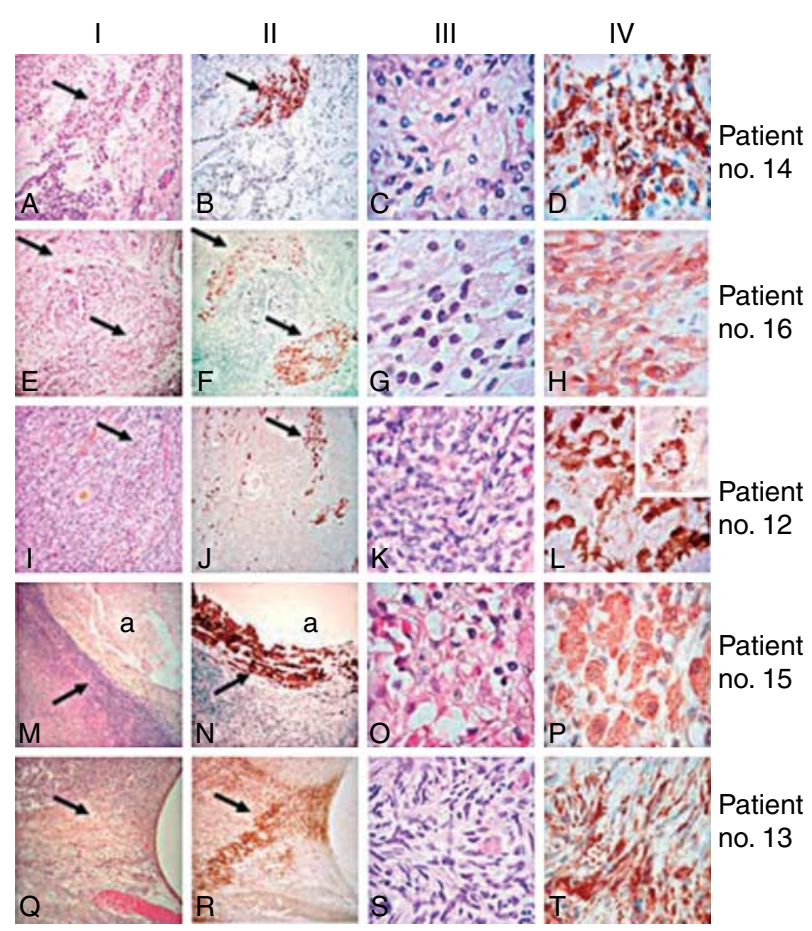

Figure 2 Histology and P450c17 $\alpha$ expression in the patients' ovaries. The patients were grouped according to a similar localization of the androgen-producing cells in the ovary. Columns I and III contain micrographs of hematoxylin-eosin-stained sections at low and high magnifications $(\times 10$ and $\times 40)$ respectively.

Columns II and IV illustrate P450c17 $\alpha$ immunoexpression, also at the same low and high magnifications. The arrows allow identifying the androgen-producing cells in the low-magnification micrographs. (A-D and E-H) ovaries of patients no. 14 and 16: large nests of cells situated in the medulla ( $A$ and $E$ ) express $\mathrm{P} 450 \mathrm{c} 17 \alpha$ ( $\mathrm{B}, \mathrm{D}$ and $\mathrm{F}, \mathrm{H}$ respectively), they have a round nucleus, abundant eosinophilic, and grossly vacuolated cytoplasm (C, D, and $\mathrm{G}, \mathrm{H}$ respectively). (I-L and M-P) ovaries of patients no. 12 and 15. Nests and cords of cells situated in the cortex, and, for patient no. 15, also arranged around a small cyst (I, K, and $\mathrm{M}, \mathrm{O}$ respectively) express $\mathrm{P} 450 \mathrm{c} 17 \alpha$ ( $\mathrm{J}, \mathrm{L}$ and $\mathrm{N}, \mathrm{P}$ respectively). These cells are large, with an abundant, vacuolated cytoplasm, and resemble luteinized cells ( $\mathrm{K}$ and $\mathrm{O})$. Inset in (L) distribution of the steroidogenic enzyme in a luteinized cell in the cortex of patient no. $12(\times 60)$. (Q-T) ovary of patient no. 13: elongated cells are dispersed in the stroma or partially adjacent to a small cyst $(\mathrm{Q})$, they are undistinguishable from fibroblasts $(\mathrm{S})$, and immunoreactive for $\mathrm{P} 450 \mathrm{c} 17 \alpha(\mathrm{R}$ and $\mathrm{T})$. 


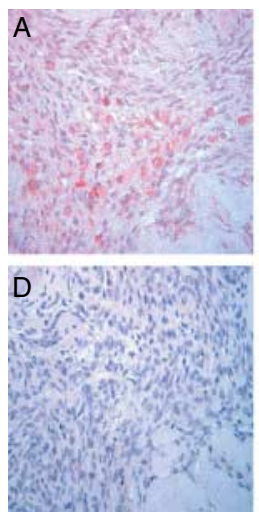

Patient no. 14

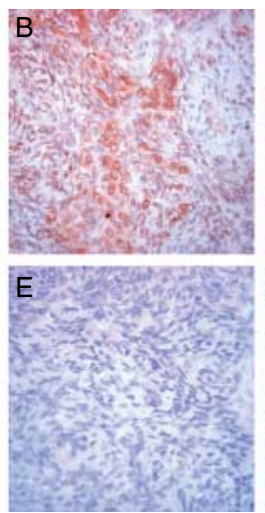

Patient no. 16

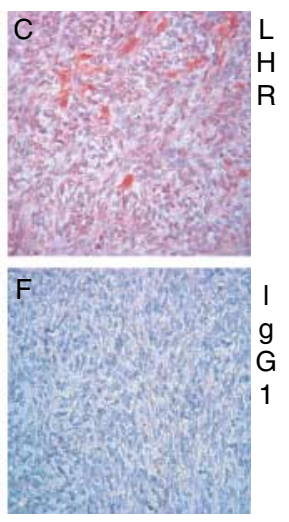

Patient no. 15
Figure 3 Immunoexpression of LHR and relative negative control (mouse IgG1, at the same concentration) in the ovarian samples from patients no. 14,15 , and 16 . The patients were grouped according to a similar localization of the androgen-producing cells in the ovary. Some of the large steroidogenic cells organized in nests in the ovarian medulla of patients no. 14 (A) and no. 16 (B) express $\mathrm{LH}$ receptors. LHR are also expressed by a fraction of the androgen-producing cells dispersed in the ovarian cortical stroma of patient no. $15(C)$. (D-F) corresponding negative controls on serial sections of the same patients (no. 14, 16, and 15 respectively) incubated with preimmune mouse IgG1 immunoglobulins at the same concentration as the primary anti-LHR antibody.

elevated androgen levels (Table 1) and mild clinical symptoms. Surprisingly, whereas hyperinsulinemia is linked to non-tumoral cause of hyperandrogenism, the BMI $\left(27.7 \pm 5.3\right.$ vs $27.9 \pm 6.5 \mathrm{~kg} / \mathrm{m}^{2}$ respectively) and the incidence of metabolic syndrome were also similar in the two groups. Thus, the presence of a metabolic syndrome cannot be useful to orientate the diagnosis toward a non-tumoral cause. In contrast to the clinical presentation, we found some significant biological differences between the two groups: testosterone, $\mathrm{E}_{2}$, and androstenedione levels were higher while FSH and LH levels were lower $(P<0.05, P<0.01, P=0.07$, $P<0.01$, and $P<0.05$ respectively) in the $\mathrm{T}$ than in the NT groups. Furthermore, we found a correlation between testosterone and $\mathrm{E}_{2}$ levels only in the NT group suggesting that the peripheral aromatization of testosterone could be the source of $\mathrm{E}_{2}$ concentrations in these NT patients. In contrast, the absence of correlation between testosterone and $\mathrm{E}_{2}$ in the $\mathrm{T}$ group suggests a tumoral source of $E_{2}$. Multivariate logistic regression analysis allowed identifying basal testosterone and basal FSH as the two significant markers. However, it must be noted that two patients in the T group, suffering from a granulosa cell tumor and a fibrothecoma, respectively, had testosterone levels just above the normal range $(1.2 \times \mathrm{N}$ and $1.5 \times \mathrm{N}$; 0.5 and $0.6 \mathrm{ng} / \mathrm{ml}$ respectively). In a previous study (4), ovarian androgen-secreting tumors were detected only in patients with testosterone levels $>1.30 \mathrm{ng} / \mathrm{ml}$, i.e. $1.5 \times \mathrm{N}$ of the testosterone assay use in our study (or $4.5 \mathrm{nmol} / \mathrm{l})$. In the context of hyperandrogenism, the diagnosis of an ovarian tumor with a level of testosterone under $0.6 \mathrm{ng} / \mathrm{ml}$, i.e. $1.2 \times \mathrm{N}$, has never been previously described. Interestingly, these two patients presented symptoms associated with hyperestrogenism suggesting that their lower testosterone levels might be secondary to an increased rate of aromatization of the androgenic substrate or a tumoral production of $E_{2}$. No patient in the NT group exhibited a serum testosterone level exceeding $3.7 \mathrm{ng} / \mathrm{ml}$, but higher testosterone levels (up to $4 \mathrm{ng} / \mathrm{ml}$ ) associated with postmenopausal non-tumoral hyperandrogenism have been reported (36). These findings explain the difficulty in identifying a critical threshold of serum testosterone suggestive of a diagnosis of ovarian neoplasm. However, we suggest that basal testosterone and basal FSH levels can be helpful in orienting the diagnosis, indeed basal testosterone levels $\geq 1.4 \mathrm{ng} / \mathrm{ml}$ have $70 \%$ specificity (CI: 39-89) and 92\% sensitivity (CI: $62-100 \%$ ) and FSH levels $\leq 35 \mathrm{IU} / \mathrm{l}$ have $92 \%$ specificity (CI: $62-100 \%$ ) and 90\% sensitivity (CI: $57-$ $100 \%$ ). Furthermore, the LR for these values in patients bearing a tumor is 8.4-10.8 times higher, respectively, giving to these markers a powerful impact. Measurement of baseline androstenedione levels in our patients did not add further information to that of testosterone levels, and we found no cases of predominantly androstenedione-secreting tumors as described previously (37). DHEA-S levels are of great interest in this context, as they were elevated only in the two patients with adrenal carcinoma, but there is a known overlap of DHEA-S levels when comparing a large cohort of adrenal androgen-secreting tumor to non-tumoral causes of androgen excess in women of all ages (20). Unfortunately, we do not have any results of testosterone decrease during low-dose dexamethasone suppression test in our cohort, considered a valuable test to distinguish androgen-secreting tumors from nontumorous hyperandrogenism in women of all ages (20).

Unlike the more easily identifiable adrenal tumors, ovarian androgen-secreting tumors are mostly small sized and thus difficult to detect by imaging techniques. Their ultrasonographic aspect depends on tumor type (38), and ultrasonography studies for Sertoli-Leydig, steroid cell tumors, and thecomas have been reported negative in premenopausal women (39-41). In our study, the calculated PPV and NPV of ultrasonography for tumor detection was 71 and $73 \%$ respectively. In contrast, ovarian MRI allowed a diagnosis of tumor in the three ultrasound-negative patients of the $\mathrm{T}$ group but also confirmed the presence of two ovarian cystic masses in two patients classed in the NT group (PPV and NPV, 78 and $100 \%$ respectively). Thus, in our study, ovarian imaging allowed adequate tumor detection.

The ovarian tumors of six of our $\mathrm{T}$ patients are known to secrete androgens, although this occurs infrequently in granulosa cell tumors (42). Two ovarian tumors found in our cohort, a gastrointestinal tumor with bilateral ovarian metastases and a serous cystadenoma, 
were not known to be steroidogenic. However, immunohistological analysis of the former showed that the metastatic tumor cells of the gastrointestinal endocrine tumor were not the primitive steroid source but instead ectopically produced hCG, stimulating the steroidogenic cells in the ovarian stroma through a paracrine mechanism (22). Histological examination of the second tumor, a serous cystadenoma, showed the presence of an adjacent zone of stromal hyperplasia, suggesting an analogous mechanism; however, no immunohistological study could be performed to confirm it. The association of epithelial ovarian tumors with interstitial androgen production in postmenopausal women has been described (43). In all these cases, histopathological examination of the tumor revealed stromal hyperplasia.

The diagnostic heterogeneity of the NT group reflects the multiple etiology of non-tumoral postmenopausal hyperandrogenism. Hyperandrogenism was related to ovarian hyperthecosis (presumed or with histological confirmation) and Cushing's or pseudo-Cushing's disease in seven patients.

Five cases remained elusive for histopathological examination: three had a normal ovarian histology and two presented a small benign ovarian cyst without stromal hyperplasia. In these five cases, IHC revealed numerous $\mathrm{P} 450 \mathrm{c} 17 \alpha$ immunopositive cells undetectable by conventional histology. Localization and morphology of the androgen-producing cells differed among patients: in two (patients no. 14 and 16) patients, large steroidogenic cells were arranged in nests at the ovarian hilus (Fig. 2), while in three (patients no. 12, 15, and 13) patients, the androgenproducing cells were situated in the cortical stroma. They had a typical steroidogenic aspect in two patients and were fibroblasts as in the other.

The morphology and location of the steroidogenic cells of cases no. 14 and 16 (Fig. 2) suggest their analogy to ovarian, androgenic, Leydig-like hilus cells (44). The aspect and cortical localization of the P450c17 $\alpha$ immunopositive cells of patients no. 12 and 15 (Fig. 2) suggest instead an origin from steroidogenic, LH-responsive luteinized theca interna cells, which persist in the cortex after follicular atresia (44) analogous to stromal hyperthecosis (45). Finally, the fibroblastic phenotype of the cortical androgenproducing cells in the ovary of patient no. 13 could be compared to that of immature thecal cells surrounding small follicles, responsive to $\mathrm{LH}$, and capable of androgen synthesis (44), suggesting an origin from this type of cell (46).

The steroidogenic enzyme P450c17 $\alpha$ lyase is under LH control (44). The LHR immunopositivity of the steroidogenic hilus cells in patients no. 15 and 16 and of the cortical stromal cells of patient no. 13 suggests that their hyperandrogenemia could be related to the elevated post-menopausal LH levels (47). However, the steroidogenic cells did not express LHR in one patient and were only partially LHR positive in three patients. This could be secondary either to receptor downregulation in the presence of continuously elevated hormone levels, as demonstrated in Leydig cells, (48, 49) or to acquired independence of the steroidogenic ovarian cells from pituitary control, analogously to some Leydig adenomas. Alternatively, destruction of available epitopes recognized by the anti-LHR antibody after formol fixation could allow labeling only of the minority of cells strongly expressing LHR.

In conclusion, postmenopausal biochemical hyperandrogenism is a rare condition that needs careful evaluation in order not to misdiagnose an underlying tumor. While the clinical phenotype does not permit discrimination between tumoral and non-tumoral conditions, the hormonal phenotypes, especially total testosterone and basal FSH levels together with adrenal androgen levels for adrenal carcinomas, can help orientating the diagnosis. Ovarian tumors are efficiently detected by MRI imaging. Finally, our findings underline the difficulty for the pathologist to identify non-tumoral ovarian sources of hyperandrogenemia and the usefulness of IHC with the appropriate antibodies to reach a diagnosis.

\section{Declaration of interest}

The authors declare that there is no conflict of interest that could be perceived as prejudicing the impartiality of the research reported.

\section{Funding}

This research did not receive any specific grant from any funding agency in the public, commercial or not-for-profit sector.

\section{Acknowledgements}

Jean-Paul Akakpo, Martine Arnoux, Nicole Athea, Yasmina Badachi, Juliane Berdah, Claire Bricaire, Marie Dominique Brunaud, Isabelle Denys, Mirabelle Detoeuf, Catherine Duflos, Anne Fortin, Michèle Felce-Dachez, Catherine Génestie, Anne Grimard, Fabrice Lecuru, Marie-Aude Lefrère-Belda, Anne-Isabelle Lemaistre, Christine Matuchansky, Bernard Paniel, Pierre-Raphael Rothschild and Joëlle Viriot.

\section{References}

1 Rothman MS \& Wierman ME. How should postmenopausal androgen excess be evaluated? Clinical Endocrinology 201175 160-164. (doi:10.1111/j.1365-2265.2011.04040.x)

2 Azziz R, Sanchez LA, Knochenhauer ES, Moran C, Lazenby J, Stephens KC, Taylor K \& Boots LR. Androgen excess in women: experience with over 1000 consecutive patients. Journal of Clinical Endocrinology and Metabolism 200489 453-462. (doi:10.1210/jc. 2003-031122)

3 Carmina E, Rosato F, Janni A, Rizzo M \& Longo RA. Extensive clinical experience: relative prevalence of different androgen excess disorders in 950 women referred because of clinical hyperandrogenism. Journal of Clinical Endocrinology and Metabolism 2006 91 2-6. (doi:10.1210/jc.2005-1457)

4 Kaltsas GA, Mukherjee JJ, Kola B, Isidori AM, Hanson JA, Dacie JE, Reznek R, Monson JP \& Grossman AB. Is ovarian and adrenal 
venous catheterization and sampling helpful in the investigation of hyperandrogenic women? Clinical Endocrinology 200359 34-43. (doi:10.1046/j.1365-2265.2003.01792.x)

5 Franks S. Polycystic ovary syndrome. New England Journal of Medicine 1995333 853-861. (doi:10.1056/NEJM199509283 331307)

6 Ireland K \& Woodruff JD. Masculinizing ovarian tumors. Obstetrical E Gynecological Survey 197631 83-111. (doi:10.1097/0000 6254-197602000-00001)

7 Fox H. Sex cord-stromal tumours of the ovary. Journal of Pathology 1985145 127-148. (doi:10.1002/path.1711450202)

8 Libe R, Fratticci A \& Bertherat J. Adrenocortical cancer: pathophysiology and clinical management. Endocrine-Related Cancer 200714 13-28. (doi:10.1677/erc.1.01130)

9 Vaikkakara S, Al-Ozairi E, Lim E, Advani A, Ball SG, James RA \& Quinton R. The investigation and management of severe hyperandrogenism pre- and postmenopause: non-tumor disease is strongly associated with metabolic syndrome and typically responds to insulin-sensitization with metformin. Gynecological Endocrinology 200824 87-92. (doi:10.1080/09513590701807100)

10 Lindgren R, Gunnarsson C, Jakobsson A \& Hammar M. Hypersecretion of ovarian androgens may be gonadotrophin dependent many years after menopause. Maturitas 200034 43-46. (doi:10. 1016/S0378-5122(99)00092-4)

11 Nakano R, Shima K, Yamoto M, Kobayashi M, Nishimori K \& Hiraoka J. Binding sites for gonadotropins in human postmenopausal ovaries. Obstetrics and Gynecology 198973 196-200.

12 Barth JH, Jenkins M \& Belchetz PE. Ovarian hyperthecosis, diabetes and hirsuties in post-menopausal women. Clinical Endocrinology 199746 123-128. (doi:10.1046/j.1365-2265. 1997.1050916.x)

13 Krug E \& Berga SL. Postmenopausal hyperthecosis: functional dysregulation of androgenesis in climacteric ovary. Obstetrics and Gynecology 200299 893-897. (doi:10.1016/S0029-7844(01) 01588-5)

14 Manieri C, Di Bisceglie C, Fornengo R, Grosso T, Zumpano E, Calvo F, Berardengo E, Volante M \& Papotti M. Postmenopausal virilization in a woman with gonadotropin dependent ovarian hyperthecosis. Journal of Endocrinological Investigation 199821 128-132.

15 Rousset P, Gompel A, Christin-Maitre S, Pugeat M, Hugol D, Ghossain MA \& Buy JN. Ovarian hyperthecosis on grayscale and color Doppler ultrasound. Ultrasound in Obstetrics $\mathcal{E}$ Gynecology 200832 694-699. (doi:10.1002/uog.6131)

16 Rittmaster RS. Polycystic ovary syndrome, hyperthecosis and the menopause. Clinical Endocrinology 199746 129-130. (doi:10. 1046/j.1365-2265.1997.8730882.x)

17 Rodin A, Thakkar H, Taylor N \& Clayton R. Hyperandrogenism in polycystic ovary syndrome. Evidence of dysregulation of 11 betahydroxysteroid dehydrogenase. New England Journal of Medicine 1994330 460-465. (doi:10.1056/NEJM199402173300703)

18 Rosenfield RL. Evidence that idiopathic functional adrenal hyperandrogenism is caused by dysregulation of adrenal steroidogenesis and that hyperinsulinemia may be involved. Journal of Clinical Endocrinology and Metabolism 199681 878-880. (doi:10. $1210 /$ jc.81.3.878)

19 Ozgun MT, Batukan C, Turkyilmaz C, Dolanbay M \& Mavili E. Selective ovarian vein sampling can be crucial to localize a Leydig cell tumor: an unusual case in a postmenopausal woman. Maturitas 200861 278-280. (doi:10.1016/j.maturitas.2008. 09.003)

20 Kaltsas GA, Isidori AM, Kola BP, Skelly RH, Chew SL, Jenkins PJ, Monson JP, Grossman AB \& Besser GM. The value of the low-dose dexamethasone suppression test in the differential diagnosis of hyperandrogenism in women. Journal of Clinical Endocrinology and Metabolism 200388 2634-2643. (doi:10.1210/jc.2002020922)

21 Pascale MM, Pugeat M, Roberts M, Rousset H, Dechaud H, Dutrieux-Berger N \& Tourniaire J. Androgen suppressive effect of GnRH agonist in ovarian hyperthecosis and virilizing tumours. Clinical Endocrinology 199441 571-576. (doi:10.1111/j.13652265.1994.tb01820.x)
22 Bachelot A, Meduri G, Baudin E, Kuttenn F \& Touraine P. Hyperandrogenism in a postmenopausal woman presenting with a metastatic ileum endocrine tumor. Fertility and Sterility 200481 675-678. (doi:10.1016/j.fertnstert.2003.07.040)

23 Suzuki T, Sasano H, Tamura M, Aoki H, Fukaya T, Yajima A, Nagura H \& Mason JI. Temporal and spatial localization of steroidogenic enzymes in premenopausal human ovaries: in situ hybridization and immunohistochemical study. Molecular and Cellular Endocrinology 199397 135-143. (doi:10.1016/03037207(93)90220-E)

24 Suzuki T, Sasano H, Kimura N, Tamura M, Fukaya T, Yajima A \& Nagura H. Immunohistochemical distribution of progesterone, androgen and oestrogen receptors in the human ovary during the menstrual cycle: relationship to expression of steroidogenic enzymes. Human Reproduction 19949 1589-1595.

25 Couzinet B, Meduri G, Lecce MG, Young J, Brailly S, Loosfelt H, Milgrom E \& Schaison G. The postmenopausal ovary is not a major androgen-producing gland. Journal of Clinical Endocrinology and Metabolism 200186 5060-5066. (doi:10.1210/jc.86.10.5060)

26 Vermeulen A. Sex hormone status of the postmenopausal woman. Maturitas 19802 81-89. (doi:10.1016/0378-5122 (80)90040-7)

27 Davison SL, Bell R, Donath S, Montalto JG \& Davis SR. Androgen levels in adult females: changes with age, menopause, and oophorectomy. Journal of Clinical Endocrinology and Metabolism 200590 3847-3853. (doi:10.1210/jc.2005-0212)

28 Rothman MS, Carlson NE, Xu M, Wang C, Swerdloff R, Lee P, Goh VH, Ridgway EC \& Wierman ME. Reexamination of testosterone, dihydrotestosterone, estradiol and estrone levels across the menstrual cycle and in postmenopausal women measured by liquid chromatography-tandem mass spectrometry. Steroids 201176 177-182. (doi:10.1016/j.steroids.2010.10.010)

29 Martin KA, Chang RJ, Ehrmann DA, Ibanez L, Lobo RA, Rosenfield RL, Shapiro J, Montori VM \& Swiglo BA. Evaluation and treatment of hirsutism in premenopausal women: an endocrine society clinical practice guideline. Journal of Clinical Endocrinology and Metabolism 200893 1105-1120. (doi:10.1210/jc.2007-2437)

30 Kominami S, Shinzawa K \& Takemori S. Immunochemical studies on cytochrome P-450 in adrenal microsomes. Biochimica et Biophysica Acta $1983 \mathbf{7 5 5} 163-169$.

31 Meduri G, Charnaux N, Loosfelt H, Jolivet A, Spyratos F, Brailly S \& Milgrom E. Luteinizing hormone/human chorionic gonadotropin receptors in breast cancer. Cancer Research 199757 857-864.

32 Markopoulos MC, Rizos D, Valsamakis G, Deligeoroglou E, Grigoriou O, Chrousos GP, Creatsas G \& Mastorakos G. Hyperandrogenism in women with polycystic ovary syndrome persists after menopause. Journal of Clinical Endocrinology and Metabolism 2011 96 623-631. (doi:10.1210/jc.2010-0130)

33 Olt $\mathrm{G} \&$ Mortel R. Hormone-producing tumors of the ovary. Endocrine-Related Cancer 19974 447-457. (doi:10.1677/erc.0. 0040447)

34 Wajchenberg BL, Albergaria Pereira MA, Medonca BB, Latronico AC, Campos Carneiro P, Alves VA, Zerbini MC, Liberman B, Carlos Gomes G \& Kirschner MA. Adrenocortical carcinoma: clinical and laboratory observations. Cancer $2000 \mathbf{8 8}$ 711-736. (doi:10.1002/(SICI)1097-0142(20000215)88:4< $711::$ AID-CNCR1 > 3.0.CO;2-W)

35 d'Alva CB, Abiven-Lepage G, Viallon V, Groussin L, Dugue MA, Bertagna X \& Bertherat J. Sex steroids in androgen-secreting adrenocortical tumors: clinical and hormonal features in comparison with non-tumoral causes of androgen excess. European Journal of Endocrinology 2008159 641-647. (doi:10. 1530/EJE-08-0324)

36 Braithwaite SS, Erkman-Balis B \& Avila TD. Postmenopausal virilization due to ovarian stromal hyperthecosis. Journal of Clinical Endocrinology and Metabolism 197846 295-300. (doi:10.1210/ jcem-46-2-295)

37 Kirk JM, Perry LA, Shand WS, Kirby RS, Besser GM \& Savage MO. Female pseudohermaphroditism due to a maternal adrenocortical tumor. Journal of Clinical Endocrinology and Metabolism 199070 1280-1284. (doi:10.1210/jcem-70-5-1280) 
38 Outwater EK, Marchetto B \& Wagner BJ. Virilizing tumors of the ovary: imaging features. Ultrasound in Obstetrics \& Gynecology 200015 365-371. (doi:10.1046/j.1469-0705.2000.00123.x)

39 Sanz OA, Martinez PR, Guarch RT, Goni MJ \& Alcazar JL. Bilateral Leydig cell tumour of the ovary: a rare cause of virilization in postmenopausal patient. Maturitas 200757 214-216. (doi:10. 1016/j.maturitas.2006.11.013)

40 Sanyal D, Taylor WG \& Otter MI. Bilateral thecomata in ovaries with normal ultrasonographic and radiological appearances, presenting with postmenopausal hirsutism and virilism. Journal of Obstetrics and Gynaecology 200323 457-458. (doi:10. 1080/0144361031000122796)

41 Cserepes E, Szucs N, Patkos P, Csapo Z, Molnar F, Toth M, Dabasi G, Esik O \& Racz K. Ovarian steroid cell tumor and a contralateral ovarian thecoma in a postmenopausal woman with severe hyperandrogenism. Gynecological Endocrinology 200216 213-216.

42 Kalfa N, Meduri G, Philibert P, Patte C, Boizet-Bonhoure B, Thibaut E, Pienkowski C, Jaubert F, Misrahi M \& Sultan C. Unusual virilization in girls with juvenile granulosa cell tumors of the ovary is related to intratumoral aromatase deficiency. Hormone Research in Pediatrics 201074 83-91. (doi:10.1159/ 000313396 )

43 Heinonen PK. Androgen production by epithelial ovarian tumours in post-menopausal women. Maturitas $1991 \quad 13$ 117-122. (doi:10.1016/0378-5122(91)90094-7)
44 Erickson GF, Magoffin DA, Dyer CA \& Hofeditz C. The ovarian androgen producing cells: a review of structure/function relationships. Endocrine Reviews 19856 371-399. (doi:10. 1210/edrv-6-3-371)

45 Rollason TP. Non-neoplastic diseases of the ovary: selected topics. Current Diagnostic Pathology 20028 172-182. (doi:10.1054/cdip. 2002.0114)

46 Magoffin DA. Ovarian theca cell. International Journal of Biochemistry \& Cell Biology 200537 1344-1349. (doi:10.1016/j.biocel. 2005.01.016)

47 Dennefors BL, Janson PO, Hamberger L \& Knutsson F. Hilus cells from human postmenopausal ovaries: gonadotrophin sensitivity, steroid and cyclic AMP production. Acta Obstetrica et Gynecologica Scandinavica $198261 \quad 413-416 . \quad$ (doi:10.3109/00016348 209156582)

48 Saez JM, Haour F \& Cathiard AM. Early hCG-induced desensitization in Leydig cells. Biochemical and Biophysical Research Communications 197881 552-558. (doi:10.1016/0006-291X(78)91570-X)

49 Saez JM. Leydig cells: endocrine, paracrine, and autocrine regulation. Endocrine Reviews 199415 574-626.

Received 30 March 2011

Revised version received 1 September 2011

Accepted 5 September 2011 